\title{
A Rasch Model Analysis of Mathematical Understanding of Prospective Mathematics Teachers in The Conic Concept
}

\author{
Eyus Sudihartinih ${ }^{1}$, Tia Purniati ${ }^{2}$, Ade Rohayati $^{3}$ \\ \{eyuss84@upi.edu ${ }^{1}$,tpurniati@upi.edu ${ }^{2}$,Aderohayati@upi.edu ${ }^{3}$ \} \\ Department of Mathematics Education, Universitas Pendidikan Indonesia, Jl. Dr. Setiabudi No. 229, \\ Bandung 40154, Indonesia ${ }^{1,2,3}$
}

\begin{abstract}
This study aims to obtain a general description of the analysis of the mathematical understanding of prospective mathematics teachers in the conic concept with Rasch models. This study was pre-experimental with a type of one-shot case study involving students of prospective mathematics teachers in the second semester. This study uses a test instrument in the form of an essay question consisting of three questions designed by a research team that is a lecturer in analytic geometry courses. The results of the analysis of the mathematical understanding of prospective mathematics teachers in analytic geometry lectures with the Rasch model show that only a small proportion of students have high mathematical understanding. The results show that the items used are not reliable and cannot be accepted to measure the mathematical understanding of prospective mathematics teachers in the conic concept.
\end{abstract}

Keywords: Mathematical Understanding, Prospective Mathematics Teachers, Analytic Geometry, Rasch Model

\section{Introduction}

Mathematical understanding is important for prospective mathematics teachers because it becomes their provision to teach at school. At least for the past 60 years, a collection of research evidence has been collected which shows the teaching benefits for understanding in mathematics [1]. Geometry is one of the important concepts in school [2]. So that prospective students of mathematics must have a good mathematical understanding of geometry. One important concept in geometry is conic because it has been studied extensively among them by Ayoub [3], Buczkowske [4], dan Nhi, Tinh, and Phuong [5].

Alternative measurements are needed to assess the quality of reliable and valid instruments including the Rasch Model, which is one of Item-Response Theory (IRT). Research on instrument testing is needed which plays an important role in it is data collection. Conclusions from appropriate research can be drawn from the research sample [6]. And the main indicators of the quality of research instruments are validity and reliability [7]. The Rasch model can determine the reliability and validity of an instrument [8] [9]. Analysis using the Rasch model can produce more precise and preferred instruments [10]. The advantages of the Rasch model are being able to provide linear scales at the same interval, predict missing data, provide more precise estimates, detect model inaccuracies and produce measurements that can be replicated [10]. Therefore, this study aims to obtain an overview of instrument analysis and mathematical 
understanding of prospective mathematics teachers in analytic geometry lectures with Rasch models.

\section{Method}

This study follows the research conducted by Sudihartinih and Wahyudin [11]. This study was pre-experimental with a type of one-shot case study involving prospective mathematics teachers in the second semester consisting of 10 men and 29 women at one university in Indonesia. The research step is the syllabus analysis by selecting concepts for research; selection of research participants, design and validation of teaching materials; instrument design and validation; implementation of learning for 3 × 250 minutes; test; data analysis; report and dissemination.

This study uses a description test instrument in the conic concept as many as three questions designed by several of the members of the research team who are lecturers of analytic geometry courses. Students fill out questions using paper and pencil within 90 minutes during the midterm. The following are the test.

First, determine the parabola equation with the focus $(10,0)$ and the directrix $x=2$. Also, determine the vertex and the length of the latus rectum. Then now the focus $F(0, a e)$ and the directrix equation (1) Prove that the simple equation of the ellipse is equation (2), and then determine the position of the points that have the nature that the difference in the distance of the point to the point $(0,-7)$ and $(0.7)$ is 8 .

$$
\begin{gathered}
y=\frac{a}{e} . \\
\frac{y^{2}}{a^{2}}+\frac{x^{2}}{b^{2}}=1
\end{gathered}
$$

General description of instrument analysis and mathematical understanding of prospective mathematics teachers in analytic geometry lectures was obtained by analyzing student answers in questionnaires using Item-Response Theory (IRT) with Rasch models assisted by Mini step software.

\section{Result and Discussion}

\subsection{Student Mathematical Understanding}

Based on the results of the study, the following scores data on students' mathematical understanding in each question.

Table 1 shows the minimum score of students' mathematical understanding is 3.00 and the maximum score is 27.00 , while the average score is 36.41 with a standard deviation of 25.03 meaning that the score is very diverse. Based on a statistical test with a difference test of two on average using the t test (using SPSS 23) on the scores of the three questions. That is question 
number 1 with question number 2, question number 1 with question number 3 , and question number 2 with question number 3 it is known that there is no significant difference at the $95 \%$ significance level.

Table 1. Scores of student mathematical understanding in each question.

\begin{tabular}{|c|c|c|c|c|}
\hline Respondent & $\begin{array}{l}\text { Question } \\
1\end{array}$ & Question 2 & Question 3 & Average Student Score \\
\hline $01 \mathrm{~L}$ & 1 & 6 & 7 & 4.67 \\
\hline $02 \mathrm{P}$ & 5 & 9 & 1 & 5.00 \\
\hline 03P & 5 & 2 & 6 & 4.33 \\
\hline $04 \mathrm{P}$ & 8 & 2 & 1 & 3.67 \\
\hline $05 \mathrm{~L}$ & 1 & 2 & 6 & 3.00 \\
\hline 06P & 1 & 2 & 0 & 1.00 \\
\hline 07L & 1 & 1 & 1 & 1.00 \\
\hline $08 \mathrm{P}$ & 7 & 1 & 9 & 5.67 \\
\hline 09L & 9 & 1 & 0 & 3.33 \\
\hline $10 \mathrm{P}$ & 5 & 2 & 1 & 2.67 \\
\hline $11 \mathrm{P}$ & 6 & 2 & 0 & 2.67 \\
\hline $12 \mathrm{P}$ & 1 & 6 & 2 & 3.00 \\
\hline $13 \mathrm{~L}$ & 1 & 0 & 2 & 1.00 \\
\hline $14 \mathrm{P}$ & 1 & 2 & 1 & 1.33 \\
\hline $15 \mathrm{P}$ & 2 & 2 & 1 & 1.67 \\
\hline $16 \mathrm{P}$ & 8 & 6 & 8 & 7.33 \\
\hline $17 \mathrm{~L}$ & 9 & 6 & 1 & 5.33 \\
\hline $18 \mathrm{~L}$ & 4 & 1 & 1 & 2.00 \\
\hline $19 \mathrm{P}$ & 2 & 1 & 1 & 1.33 \\
\hline $20 \mathrm{P}$ & 1 & 1 & 1 & 1.00 \\
\hline $21 \mathrm{P}$ & 1 & 1 & 9 & 3.67 \\
\hline $22 \mathrm{P}$ & 8 & 2 & 9 & 6.33 \\
\hline $23 \mathrm{P}$ & 2 & 2 & 1 & 1.67 \\
\hline $24 \mathrm{P}$ & 1 & 1 & 9 & 3.67 \\
\hline $25 \mathrm{~L}$ & 1 & 1 & 1 & 1.00 \\
\hline $26 \mathrm{~L}$ & 1 & 1 & 2 & 1.33 \\
\hline $27 \mathrm{~L}$ & 9 & 9 & 9 & 9.00 \\
\hline $28 \mathrm{P}$ & 1 & 9 & 1 & 3.67 \\
\hline $29 \mathrm{P}$ & 9 & 9 & 6 & 8.00 \\
\hline $30 \mathrm{P}$ & 9 & 2 & 1 & 4.00 \\
\hline $31 \mathrm{P}$ & 1 & 1 & 1 & 1.00 \\
\hline $32 \mathrm{P}$ & 4 & 2 & 1 & 2.33 \\
\hline $33 \mathrm{P}$ & 1 & 1 & 1 & 1.00 \\
\hline $34 \mathrm{P}$ & 5 & 6 & 4 & 5.00 \\
\hline $35 \mathrm{P}$ & 1 & 4 & 6 & 3.67 \\
\hline $36 \mathrm{P}$ & 5 & 6 & 1 & 4.00 \\
\hline $37 \mathrm{P}$ & 9 & 9 & 9 & 9.00 \\
\hline $38 \mathrm{P}$ & 1 & 1 & 1 & 1.00 \\
\hline $39 \mathrm{P}$ & 7 & 9 & 1 & 5.67 \\
\hline Average score & 3.95 & 3.36 & 3.15 & 36.41 \\
\hline SD & 3.20 & 2.99 & 3.26 & 25.03 \\
\hline
\end{tabular}

\subsection{Reliability Item}


According to Figure 1, the mean measure is -0.12 means that the average score of students' mathematical understanding is negative. The average value which is less than logit 0.0 indicates the tendency of students who cannot answer the questions [10]. Cronbach Alpha value 0.56 means poor reliability [12]. The value of Person reliability is 0.00 which means weak [10]. Thus, the consistency of students is weak.

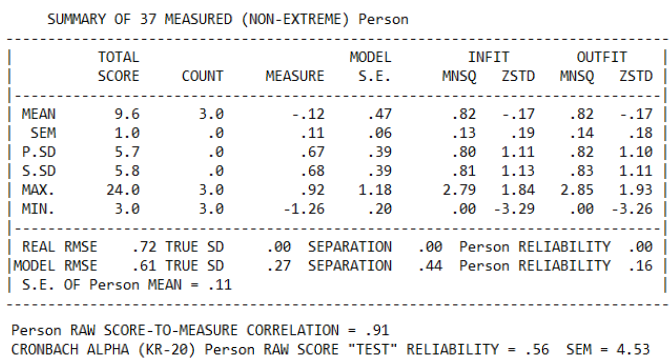

Fig. 1. Measured Person.

According to Figure 2, the mean measure +0.00 means that the average item is 0.00 so the average question is medium. Item reliability value is 0.00 which means weak [10]. Thus, the quality of the question item is weak.

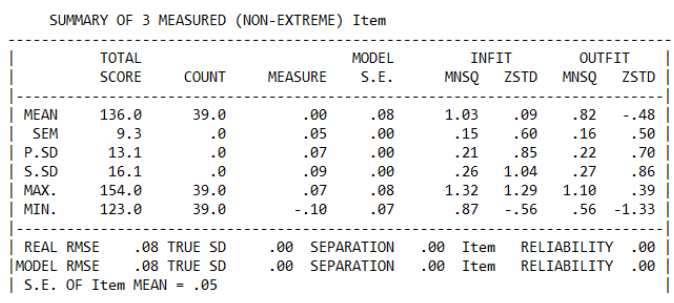

Fig. 2. Measured Item.

In Figure 3, the Guttman scalogram pattern shows the answer of each student in a question item. The items are sorted according to the easiest questions on the left to the most difficult questions located on the right side of the Guttman scalogram. Students are sorted from students who have the highest score at the top of the Guttman scalogram. If seen further, the students who have the highest score are $27 \mathrm{~L}$ and $37 \mathrm{P}$, while the students with the lowest scores are 5 people, namely 20P, 25L, 31P, 33P, 38P. There are students who look inconsistent in their answers, for example, 08P students because of irregular scores from high to low scores. This means that he can answer more difficult questions, but easy questions cannot. 


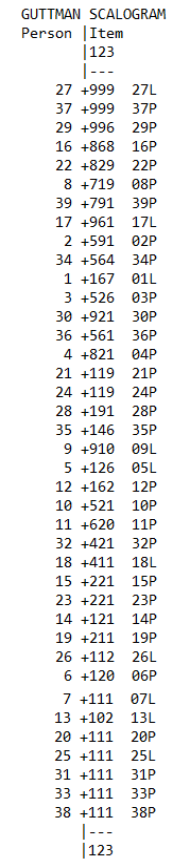

Fig. 3. Gutmann Scalogram.

\subsection{Item Validity}

Based on Figure 4 about measure order items, MNSQ 1.01 INFIT mean and MNSQ 0.82 mean OUTFIT, if it is closer to 1.00 then it is better, meaning this question has good conditions for measurement [10]. The ZSTD INFIT mean is 0.1 and the mean ZSTD OUTFIT is -0.5. If the ZSTD value is closer to 0.0 , the better means that the data has a logical estimate [10]. Item I0001 with +0.07 logit shows item number 3 is the most difficult to answer correctly by students, while item I0001 with -0.1 logit shows items that are most easily solved by students [10].

If the value is in PTMea Corr. positive $(+)$ then the item measures the construct, and conversely. So if PTMea Corr. negative (-) then the item must be discarded or refined because it is too difficult/easy or does not lead to the question (out of focus) [8]. The findings of this study indicate that all items that have PTMea Corr. positive so that no items are discarded or revised.

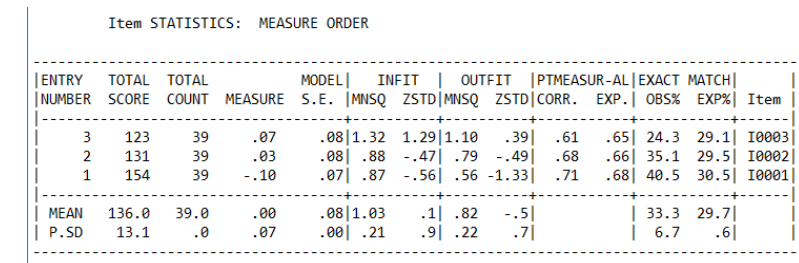

Fig. 4. Item statistic: measure order. 


\subsection{Analysis of Mathematical Understanding of Prospective Mathematics Teacher Students}

The Person-Item Distribution Map (PIDM) describes the ability of students to be latent in responding to the difficulty of an item [13]. As shown in Figure 5 and Figure 6, almost all students have difficulty answering questions, except students $27 \mathrm{~L}$ and $37 \mathrm{P}$. Although the third question is the most difficult, but the third position is close, so all the questions are difficult.

OUTFIT mean square (MNSQ) must be in the interval between 0.60 and 1.40 and the ZSTD INFIT and OUTFIT values must be in the interval between -2 to +2 [10]. Based on Figure Person statistics: Order measurement, more than half of the students outside the interval, for example, students 38P, 33P, 31P. This means that these students are not logical in answering questions. In the next table, diagnostic samples from students are given with illogical answers.

Based on the Analysis of Mathematical Understanding of Prospective Mathematics Teacher Students it is known that more than half the number of students is still low. Therefore, further research is still needed to improve the Mathematical Understanding of Prospective Mathematics Teacher Students.

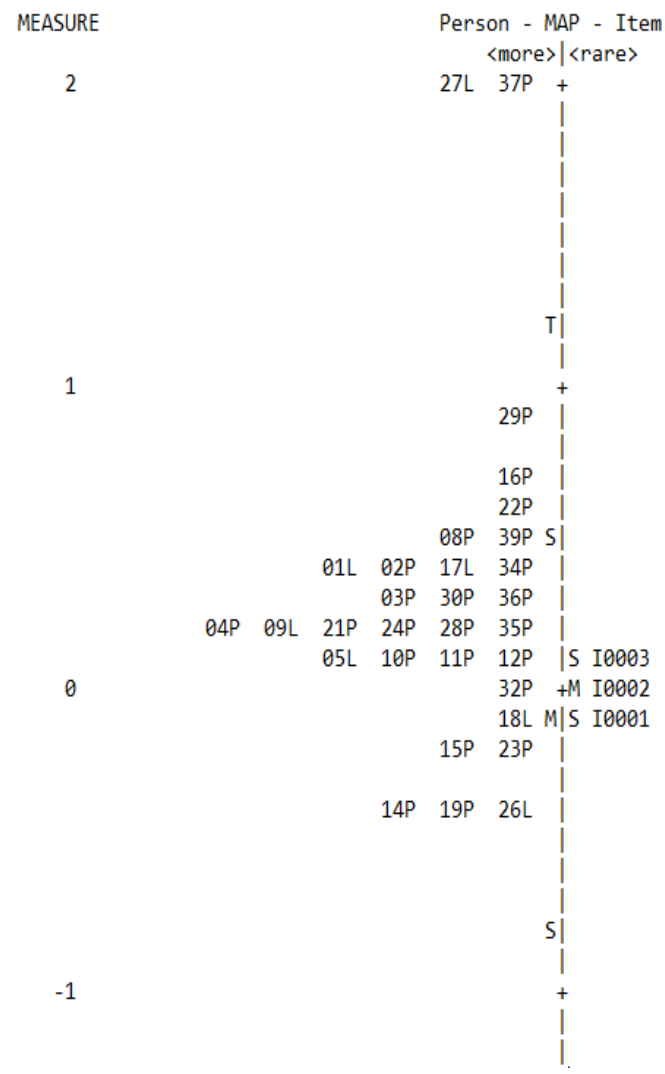

Fig. 5. Person-item measurement. 
Person STATISTICS: MEASURE ORDER

\begin{tabular}{|c|c|c|c|c|c|c|c|c|c|c|c|c|c|}
\hline ENTRY & TOTAL & TOTAL & & MODELI & & NFIT I & OUT & TFIT IP & PTMEASL & UR-AL & |EXACT | & MATCH & \\
\hline NUMBER & SCORE & COUNT & MEASURE & S.E. I & MNSQ & ZSTD|I & MNSQ & ZSTDIC & CORR. & EXP. I & O OBS\% & 6 EXP\%| & Person \\
\hline 27 & 27 & 3 & 2.08 & $1.49 \mid$ & MAXI & IMUM ME, & EASURE & & .00 & $.00 \mid$ & |100.0 & 100.0 & $27 \mathrm{~L}$ \\
\hline 37 & 27 & 3 & 2.08 & 1.49 & MAXI & IMUM ME, & EASURE & & .00 & .00 & 100.0 & 100.0 & $37 \mathrm{P}$ \\
\hline 29 & 24 & 3 & .92 & .36 & .63 & $.17 \mid$ & .57 & .11 & .71 & $.11 \mid$ & | 0 & $\mid 13.1$ & $29 \mathrm{P}$ \\
\hline 16 & 22 & 3 & .74 & .27 & .19 & $-.90 \mid$ & .17 & $-.89 \mid$ & .25 & .15 & 33.3 & $9.0 \mid$ & $16 \mathrm{P}$ \\
\hline 22 & 19 & 3 & .57 & .22 & 1.34 & .68 & 1.24 & .55 & .12 & |19| & .0 & 16.0 & $22 \mathrm{P}$ \\
\hline 8 & 17 & 3 & .48 & .20 & 1.47 & .94 & 1.38 & $.79 \mid$ & .01 & $.20 \mid$ & .0 & $\mid 12.1$ & $08 \mathrm{P}$ \\
\hline 39 & 17 & 3 & .48 & $.20 \mid$ & 1.19 & .52 & 1.12 & $.39 \mid$ & .52 & .20 & .0 & 12.1 & $39 \mathrm{P}$ \\
\hline 17 & 16 & 3 & .44 & .20 & .89 & $-.07 \mid$ & .89 & $-.05 \mid$ & .92 & .21 & .0 & $\mid 12.2$ & $17 \mathrm{~L}$ \\
\hline 2 & 15 & 3 & .40 & .20 & 1.16 & .48 & 1.13 & .42 & .26 & $.21 \mid$ & .0 & 11.5 & $02 \mathrm{P}$ \\
\hline 34 & 15 & 3 & .40 & .20 & .09 & $-3.29 \mid$ & .09 & $-3.26 \mid$ & .26 & $.21 \mid$ & 33.3 & $\mid 11.5$ & $34 \mathrm{P}$ \\
\hline 1 & 14 & 3 & .36 & .20 & 1.24 & .63 & 1.25 & .65 & -.99 & .21 & | .0 & 10.7 & $01 \mathrm{~L}$ \\
\hline 3 & 13 & 3 & .32 & .20 & .38 & $-1.50 \mid$ & .39 & $-1.46 \mid$ & .01 & .21 & 33.3 & 6.6 & $03 \mathrm{P}$ \\
\hline 30 & 12 & 3 & .28 & $.20 \mid$ & 1.07 & .30 & 1.03 & $.24 \mid$ & .99 & .21 & .0 & 4.7 & $30 P$ \\
\hline 36 & 12 & 3 & .28 & .20 & .44 & -1.18 & .47 & -1.08 & .57 & .21 & 33.3 & 4.7 & $36 \mathrm{P}$ \\
\hline 4 & 11 & 3 & .24 & $.21 \mid$ & .82 & -.14 & .78 & -.20 & .99 & .21 & .0 & 2.0 & O4P \\
\hline 21 & 11 & 3 & .24 & .21 & 2.30 & 1.84 & 2.45 & $1.93 \mid$ & -.71 & $.21 \mid$ & .0 & 2.0 & $21 \mathrm{P}$ \\
\hline 24 & 11 & 3 & .24 & .21 & 2.30 & 1.84 & 2.45 & $1.93 \mid$ & -.71 & .21 & .0 & 2.0 & $24 \mathrm{P}$ \\
\hline 28 & 11 & 3 & .24 & .21 & 2.06 & 1.60 & 2.05 & 1.55 & -.25 & .21 & .0 & 2.0 & $28 \mathrm{P}$ \\
\hline 35 & 11 & 3 & .24 & $.21 \mid$ & .91 & $.03 \mid$ & .89 & $.01 \mid$ & -.99 & .21 & .0 & 2.0 & $35 \mathrm{P}$ \\
\hline 9 & 10 & 3 & .20 & .22 & 1.72 & 1.12 & 1.61 & $.97 \mid$ & .99 & $.20 \mid$ & .0 & 2.0 & $09 \mathrm{~L}$ \\
\hline 5 & 9 & 3 & .15 & .23 & 1.04 & .31 & 1.12 & $.41 \mid$ & -.83 & .19 & .0 & 2.0 & $05 \mathrm{~L}$ \\
\hline 12 & 9 & 3 & .15 & .23 & .93 & .16 & .90 & .14 & -.43 & .19 & .0 & 2.0 & $12 \mathrm{P}$ \\
\hline 10 & 8 & 3 & .09 & .25 & .30 & $-.81 \mid$ & .29 & $-.75 \mid$ & 1.00 & .18 & 33.3 & $|16.3|$ & $10 \mathrm{P}$ \\
\hline 11 & 8 & 3 & .09 & .25 & .79 & .05 & .78 & .06 & 1.00 & .18| & 33.3 & 16.3 & $11 \mathrm{P}$ \\
\hline 32 & 7 & 3 & .02 & .27| & .19 & $-.84 \mid$ & .19 & $-.74 \mid$ & 1.00 & .16 & 33.3 & 16.5 & $32 \mathrm{P}$ \\
\hline 18 & 6 & 3 & -.07 & .32 & .42 & $-.13 \mid$ & .37 & $-.13 \mid$ & .96 & .14 & .0 & 24.6 & $18 \mathrm{~L}$ \\
\hline 15 & 5 & 3 & -.19 & $.40 \mid$ & .07 & $-.77 \mid$ & .09 & $-.69 \mid$ & .71 & $.11 \mid$ & 66.7 & 24.1 & $15 \mathrm{P}$ \\
\hline 23 & 5 & 3 & -.19 & $.40 \mid$ & .07 & $-.77 \mid$ & .09 & $-.69 \mid$ & .71 & .11 & 66.7 & $24.1 \mid$ & $23 \mathrm{P}$ \\
\hline 14 & 4 & 3 & -.44 & .62 & . .28 & $-.26 \mid$ & .30 & $-.24 \mid$ & -.25 & $.07 \mid$ & 66.7 & 70.3 & $14 \mathrm{P}$ \\
\hline 19 & 4 & 3 & -.44 & .62 & |.19 & $|-.43|$ & |.17 & $-.47 \mid$ & | .96 & $.07 \mid$ & 66.7 & 70.31 & 19P \\
\hline 26 & 4 & 3 & -.44 & .62 & . .31 & -.22 & .35 & $-.15 \mid$ & | - -.71 & $.07 \mid$ & 66.7 & 70.3 & | $26 \mathrm{~L}$ \\
\hline 6 & 3 & 3 & -1.26 & 1.18 & 2.73 & 1.32 & 2.79 & 1.34 & .26 & .04 & 33.3 & 78.2 & O6P \\
\hline 7 & 3 & 3 & -1.26 & 1.18 & .00 & -1.42 & .00 & -1.42 & .00 & .04 & 100.0 & 78.2 & $07 \mathrm{~L}$ \\
\hline 13 & 3 & 3 & -1.26 & 1.18 & 2.79 & 1.34 & 2.85 & 1.36 & -.26 & .04 & 33.3 & 78.2 & | $13 \mathrm{~L}$ \\
\hline 20 & 3 & 3 & -1.26 & 1.18 & .00 & -1.42 & .00 & -1.42 & .00 & .04 & 100.0 & 78.2 & $20 P$ \\
\hline 25 & 3 & 3 & -1.26 & 1.18 & .00 & -1.42 & .00 & -1.42 & .00 & .04 & 100.0 & 78.2 & $25 \mathrm{~L}$ \\
\hline 31 & 3 & 3 & -1.26 & 1.18 & 1.00 & -1.42 & 1.00 & -1.42 & .00 & .04 & 100.0 & 78.2 & $31 P$ \\
\hline 33 & 3 & 3 & -1.26 & 1.18 & 1.00 & -1.42 & 1.00 & -1.42 & .00 & .04 & 100.0 & 78.2 & | $33 \mathrm{P}$ \\
\hline 38 & 3 & 3 & -1.26 & 1.18 & 1.00 & -1.42 & 1.00 & -1.42 & |.00 & & 100.0 & 78.2 & | $38 \mathrm{P}$ \\
\hline MEAN & 10.5 & 3.0 & .00 & .53 & \begin{tabular}{|l}
.82 \\
|
\end{tabular} & -.2 & .82 & -.2 & & & 33.3 & 29.7 & \\
\hline P.SD & 6.8 & .0 & .81 & .44 & .80 & 1.1 & .82 & 1.1 & & & 37.2 & 30.81 & \\
\hline
\end{tabular}

Fig. 6. Person statistics: Order measurement.

\section{Conclusion}

The results of the analysis of the mathematical understanding of prospective mathematics teachers in analytic geometry lectures with the Rasch model show that only a small proportion of students have high mathematical understanding. The results of the Rasch model measurement to examine the instruments show that the items used are not reliable and cannot be accepted to measure the mathematical understanding of prospective mathematics teachers in analytic geometry lectures. So that further research is needed on the instruments and mathematical understanding of prospective mathematics teachers in analytic geometry lectures with the Rasch model. 
Acknowledgments. We would like to thank students of the mathematics education department of Universitas Pendidikan Indonesia and Directorate General of Ministry of Research, Technology and Higher Education of the Republic Indonesia for their support in this study who supports this research.

\section{References}

[1] Silver, E. A., Mesa, V. M., Morris, K. A., Star, J. R., and Benken, B. M.: Teaching mathematics for understanding: An analysis of lessons submitted by teachers seeking NBPTS certification. American Educational Research Journal, Vol. 46, No. 2, pp. 501-531 (2009)

[2] NCTM: Principles, and standards for school mathematics. National Council of Teachers of Mathematics, US (2000)

[3] Ayoub, A. B.: The director circle of a central conic section. Mathematics and Computer Education, Vol. 41, No. 2, pp. 136-142 (2011)

[4] Buczkowske, L.: Understanding algebraic concepts and conics. The Mathematics Teacher, Vol. 87, No. 4, pp. 297-298 (1994)

[5] Nhi D. M., Tinh, T.T., and Phuong, P. M.: Some new identities on the conic sections. Journal of Science and Arts Year, Vol. 28, No. 3, pp. 199-210 (2014)

[6] Creswell, J. W.: Educational research: Planning, conducting and evaluating quantitative and qualitative research. Pearson Education, US. pp. 146-166 (2012)

[7] Kimberlin, C.L., and Winterstein, A.G.: Validity and reliability of measurement instruments used in research. American Journal of Health-System Pharmacy, Vol. 65, No. 23, pp. 2276-2284 (2008)

[8] Bond, T. G. and Fox, C. M.: Applying the Rasch model: Fundamental measurement in the human sciences. Lawrence Erlbaum Associates Publishers. (2007)

[9] Razali, S.N. and Shahbodin, F.: Questionnaire on the perception of online collaborative learning: Measuring validity and reliability using Rasch model. 4th International Conference on User Science and Engineering, IEEE. pp. 199-203 (2016)

[10] Sumintono, B. and Widhiarso, W.: Aplikasi model Rasch untuk penelitian ilmu-ilmu sosial. Trimkom Publishing House, Indonesia (2014)

[11] Levels, G. T.: Analysis of students' self efficacy reviewed by geometric thinking levels and gender using Rasch model. Journal Of Engineering Science And Technology, Vol. 14. No. 1, pp. 509-519 (2019)

[12] Fisher, W. P. J.: Rating scale instrument quality criteria. Rasch measurement transactions. 2007. [Online]. Available: http://www.rasch.org/rmt/rmt211m.htm. [9 November 2018].

[13] Rashid, R.A., Abdullah, R., Ghulman, H.A., and Masodi, M.S.: Application of Rasch-based ESPEGS model in measuring generic skills of engineering students: A new paradigm. WSEAS Transactions on Advances in Engineering Education, Vol. 5. No. 8, pp. 591-602 (2008) 